\title{
Asociación de vector del VNO e hidrófito invasor: Culex pipiens Linnaeus, 1758 y Ludwigia grandiflora (Michaux) Greuter \& Burdet en el marjal de Xeraco-Xeresa, Valencia
}

Pedro María Alarcón-Elbal ${ }^{1}$, José Marín Sánchez Murillo², Sarah Delacour Estrella ${ }^{1,3}$, Ignacio Ruiz Arrondo ${ }^{1,3}$, Rocío Pinal Prieto ${ }^{3} \&$ Javier Lucientes Curdi ${ }^{1}$.

1 Departamento de Patología Animal, Unidad de Parasitología y Enfermedades Parasitarias. Facultad de Veterinaria, Universidad de Zaragoza, España. C/ Miguel Servet 177. 50013 Zaragoza.

2 Departamento de Parasitología. Laboratorio Regional de Sanidad Animal. Servicio de Sanidad Animal. Consejería de Agricultura, Desarrollo Rural, Medio Ambiente y Energía. Gobierno de Extremadura, España. Camino de Sta. Engracia, s/n. 06007 Badajoz.

3 Quimera Biological Systems S.L. Polígono Industrial Malpica-Alfindén. C/ Olivo n 14 nave 6. 50171 La Puebla de Alfindén, Zaragoza.

Correspondencia
P.M. Alarcón-Elbal
E-mail: pedro.alarcon@uv.es
Recibido: 24 febrero 2013
Aceptado: 15 marzo 2013
Publicado on-line: 8 abril 2013

\section{Resumen}

Se reporta la estrecha relación entre uno de los principales vectores del virus del Nilo Occidental (VNO), Culex pipiens (Diptera, Culicidae), y la planta invasora acuática Ludwigia grandiflora (Spermatophyta, Onagraceae) en el marjal de Xeraco-Xeresa, un humedal al sur de la provincia de Valencia. Los hidrófitos alóctonos desempeñan en ocasiones un papel primordial en la proliferación descontrolada de poblaciones de mosquitos y, en consecuencia, también en la transmisión y propagación de muchas enfermedades emergentes y reemergentes transmitidas por estos dípteros. Teniendo en cuenta la situación geográfica de este humedal y los diferentes factores climáticos y biológicos, la aparición de una epidemia del VNO con incidencia humana es un hecho más que probable en esta vertiente mediterránea del país.

Palabras clave: Culicidae, Plantas invasoras acuáticas, Virus del Nilo Occidental (VNO), Enfermedades transmitidas por artrópodos, Valencia, España.

\begin{abstract}
Linkage between WNV vector and invasive alien hydrophyte: Culex pipiens Linnaeus, 1758 and Ludwigia grandiflora (Michaux) Greuter \& Burdet on Xeraco-Xeresa marsh, Valencia

The close relationship between one of the main vectors of West Nile virus (WNV), Culex pipiens (Diptera, Culicidae), and invasive aquatic plant Ludwigia grandiflora (Spermatophyta, Onagraceae) is reported on Xeraco-Xeresa marsh, a wetland in the south of the province of Valencia. Allochthonous hydrophytes sometimes play a major role in the uncontrolled proliferation of culicid populations and, consequently, also in the transmission and spread of many emerging and re-emerging mosquito-borne diseases. Considering the location of the wetland and the different climatic and biological factors, the emergence of West Nile virus infection outbreak in humans is a fairly likely at this Mediterranean side of the country.
\end{abstract}

Key words: Culicidae, Invasive aquatic plants, West Nile virus (WNV), Arthrophod-borne diseases, Valencia, Spain. 


\section{Introducción}

El virus del Nilo Occidental (VNO) está considerado en la actualidad como uno de los arbovirus más ampliamente distribuidos del mundo (Kramer et al. 2008). El ciclo natural (enzoótico o selvático) de este flavivirus incluye la participación de aves silvestres y domésticas, migratorias y residentes, las cuales tienen el papel de hospedadores o reservorios amplificadores primarios, si bien las migratorias son las principales causantes de la introducción del virus en nuevas regiones (Rappole et al. 2000). Los mosquitos ornitófilos, principalmente los del género Culex Linnaeus, 1758 y dentro de éstos la especie Culex pipiens Linnaeus, 1758, que se alimentan de aves virémicas son infectados y transmiten el virus a otros hospedadores, actuando como vector primario (Savage et al. 1999). Mientras que algunas aves desarrollan graves cuadros clínicos con elevada mortalidad como es el caso de los córvidos (Eidson et al., 1999), la mayoría sufren infecciones asintomáticas, sobreviviendo a la infección y desarrollando inmunidad. En el ciclo urbano (epizoótico), los seres humanos y otros mamíferos (la mayoría equinos), se consideran hospedadores incidentales y no son capaces de amplificar el virus, ya que presentan viremias bajas (Fernández-Salas et al. 2007). En éstos la enfermedad suele cursar inespecíficamente, en la mayoría de los casos con leves accesos febriles, aunque pueden evolucionar a presentaciones clínicas considerables como encefalitis o encefalomielitis y causar la muerte del individuo (Hayes et al. 2005).

El número de casos de infección con VNO se ha incrementado con el tiempo, lo que indica que la transmisión sigue en evolución y que se ha establecido como un virus endémico y epidémico en muchas regiones geográficas. Una de las zonas más castigadas ha sido Norteamérica. En EE.UU. la enfermedad se detectó por vez primera en Nueva York en 1999 (Nash et al. 2001), pero ha sido en 2012 cuando la alerta epidemiológica ha alcanzado las cotas más altas, pues a fecha de 11 de diciembre de este mismo año 48 estados habían reportado infecciones por el VNO en personas, aves o mosquitos, con 5387 casos de la enfermedad en humanos y una mortalidad que ascendía a las 243 personas fallecidas (CDC, 2012). En Europa el virus ha sido menos patógeno, originando casos aislados en aves silvestres y caballos (Hubálek,
2000; Zeller \& Schuffenecker, 2004), aunque desde el comienzo del nuevo milenio ha aumentado su actividad en el continente, con un significativo incremento de brotes durante la década actual en la cuenca mediterránea y el este de Europa (Vázquez González, 2010). En lo que respecta a España, la primera vez que se detectó infección humana fue en 2004, en un caso de meningitis (Kaptoul et al. 2007). En septiembre de 2010, se diagnosticaron otros 2 casos de meningoencefalitis en varones en la provincia de Cádiz, coincidiendo con un brote de VNO que afectó a 44 caballos de las provincias de Cádiz, Sevilla y Málaga y produjo 9 muertes en estos animales (Pérez Ruiz et al. 2011). Al margen de ello, estudios realizados en Cataluña han evidenciado la existencia de anticuerpos en la población humana del Delta del Ebro (Tarragona), lo cual revela casos pasados de contagio (Bofill et al. 2006).

En este contexto las zonas húmedas son los ambientes ideales para el mantenimiento del ciclo enzoótico de esta arbovirosis (Alarcón-Elbal et al. 2012), ya que en ellas se yuxtapone la existencia de niveles hídricos permanentes o semipermanentes con la presencia de una biodiversa avifauna y elevadas poblaciones de culícidos vectores. Estos focos de actividad del virus son generalmente silenciosos y permanecen indetectables, pero podrían activarse y expandirse dando lugar a ciclos urbanos bajo determinadas circunstancias, aumentando la circulación viral debido a factores favorables tanto abióticos como bióticos (Higgs et al 2004). Uno de estos factores bióticos es la presencia de especies vegetales acuáticas exóticas, las cuales crecen sin mesura una vez introducidas en los nuevos hábitats. De forma general, el principal efecto de estos invasores radica en una elevada producción de biomasa que suele llegar a impedir la penetración de la luz al interior del cuerpo de agua, imposibilitando la fotosíntesis en el fondo y tornándose por consiguiente el ambiente anóxico. El entorno se altera rápidamente y se inviabiliza la existencia de la mayoría de las especies que previamente formaban parte del ecosistema, entre ellas los macro invertebrados acuáticos y la fauna asociada. Además, aumenta la evapotranspiración, la temperatura del agua y las cargas internas de nutrientes (Madsen, 2009). El paradigma de este tipo de invasiones en España lo ha constituido Eichhornia crassipes (Mart.) Solms 1883, más conocido como jacinto de agua o camalote, el cual 
ha provocado en los últimos años la implantación de un costoso plan integral de lucha en la cuenca del Guadiana a su paso por Badajoz (Ruiz Téllez et al. 2008).

Todas estas transformaciones producidas por hidrófitos invasores terminan desembocando en una gran eutrofización del medio. Se produce un cambio en las características físico-químicas del agua, pues también influyen sobre el flujo, ralenti- zando la corriente allá donde se establecen, pudiendo obstruir la navegación y otras actividades asociadas a vías fluviales y ríos, proporcionando, al mismo tiempo, unas condiciones ideales para que se produzcan proliferaciones desmedidas de mosquitos. Los culícidos, artrópodos cuya estrategia reproductiva es claramente oportunista, encuentran en estos nuevos sistemas modificados por los invasores un nicho de características
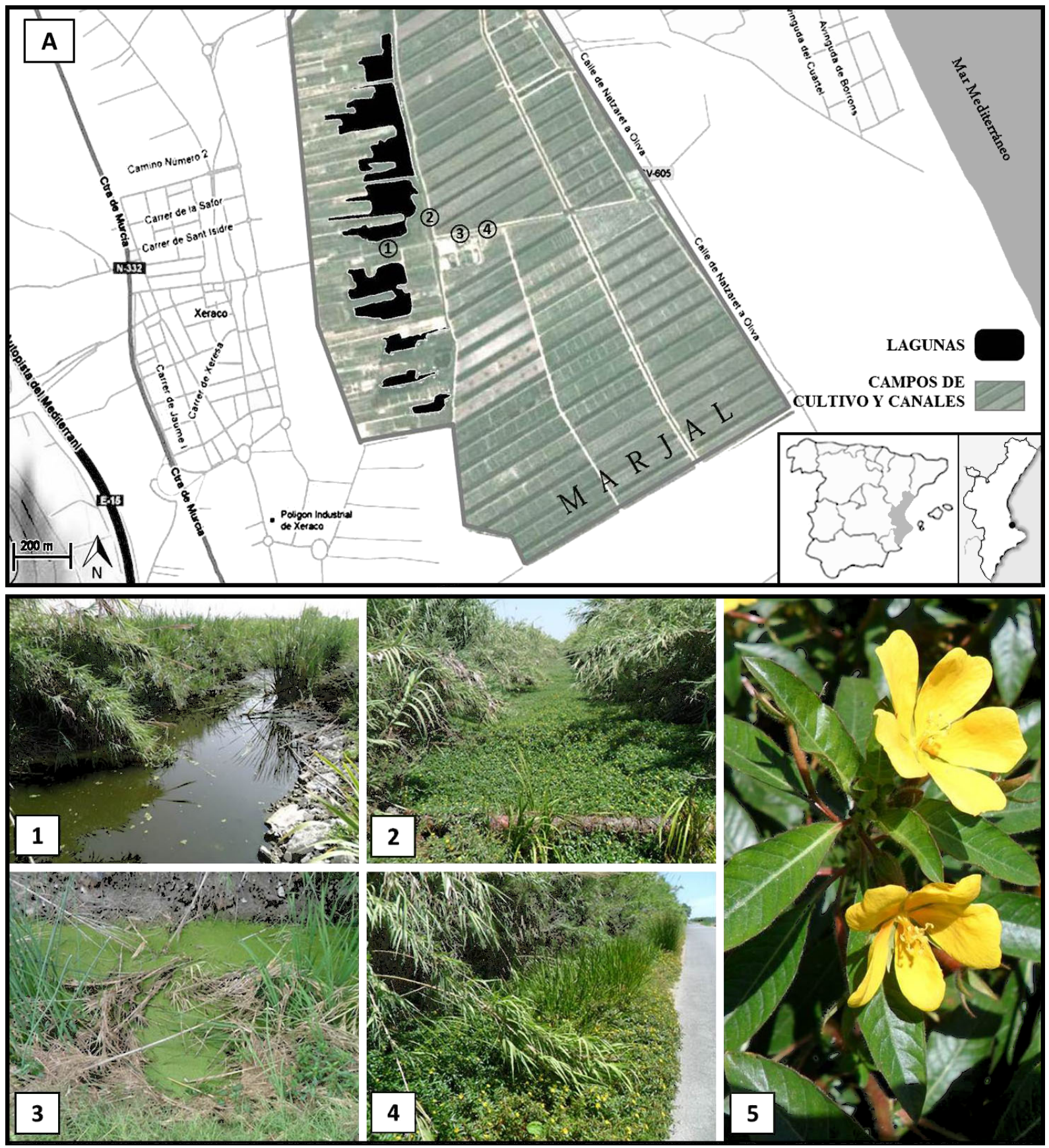

Figura 1. Área de estudio (A) y zonas de muestreo, donde (1) Zona 1, (2) Zona 2, (3) Zona 3, (4) Zona 4 y (5) detalle del hidrófito Ludwigia grandiflora.

Figure 1. Study area (A) and sampling zones, where (1) Zone 1, (2) Zone 2, (3) Zone 3, (4) Zone 4 and (5) detail of the hydrophyte Ludwigia grandiflora. 
inmejorables para su desarrollo, sobre todo aquellas especies de elevada ubicuidad, que en ocasiones son a su vez vectores de importantes agentes patógenos (Alarcón-Elbal, 2013).

\section{Material y métodos}

\section{Área de estudio}

Desde el Departamento de Patología Animal (Parasitología y Enfermedades Parasitarias) de la Universidad de Zaragoza se ha realizado una vigilancia entomológica de vectores potenciales del VNO en España durante 2012, por medio de prospecciones periódicas en determinadas zonas del litoral valenciano. Uno de los enclaves prospectados ha sido el marjal de Xeraco-Xeresa, una zona húmeda de la Comunidad Valenciana incluida a su vez dentro del marjal de La Safor, el cual comprende los términos municipales de Tavernes de la Valldigna, Xeraco, Xeresa y Gandía (Peña et al.
2005). Esta superficie posee un importante valor ecológico y botánico, pues comprende un gran número de ullales o surgencias de agua, acequias, canales, retornos de riego y lagunas con una diversidad de macrófitos sumergidos única en la Comunidad Valenciana. Este marjal valenciano es, además, de gran valor por su alta biodiversidad y por una situación biogeográfica que lo hace fundamental en las rutas migratorias de numerosas especies de aves, siendo, con todo, este humedal de inestimable complejidad y gran valor ecológico (Villena \& Romo, 2001). La circulación del agua está controlada por el ser humano y, para ello, una compleja red de acequias y canales distribuye y regula los niveles hídricos del aguazal para permitir el cultivo y drenar los excedentes (Rodrigo et al. 2001).

Dentro de esta área, se eligieron cuatro estaciones o zonas de muestreo, de características marcadamente disparejas, aunque espacialmente próximas entre sí (Fig.1) (Tabla 1).

\begin{tabular}{|c|c|c|c|}
\hline ZONA & TIPO DE ESTACIÓN & LOZALIZACIÓN GPS & ALTITUD (msnm) \\
\hline \multirow[b]{2}{*}{1} & ACEQUIA DEL CAMINÀS & 30S 741385.05 E 4324310.21 & 2 \\
\hline & \multicolumn{3}{|c|}{$\begin{array}{l}\text { Comunidad pobre en especies que queda caracterizada por Typha dominguensis y Schoenoplectus } \\
\text { lacustris subsp. glaucus y, en menor proporción, elementos de la clase como Phragmites australis o } \\
\text { Schoenoplectus litoralis. Esta asociación forma una banda más o menos continua en la zona más } \\
\text { próxima al agua en canales y acequias, siendo capaz de soportar cierto grado de salinidad (Soriano } \\
\text { Guarinos, 1995). }\end{array}$} \\
\hline \multirow[b]{2}{*}{2} & ACEQUIA TRAVESSERA & 30S 741754.22 E 4324408.67 & 1 \\
\hline & \multicolumn{3}{|c|}{$\begin{array}{l}\text { Ludwigia grandiflora es un neófito que en los últimos años ha sufrido una importante expansión. Forma } \\
\text { comunidades muy aparentes en la época de floración, prácticamente monoespecíficas, que se sitúan } \\
\text { tapizando ríos, canales y charcos de aguas calmas y contaminadas (Soriano Guarinos, 1995). }\end{array}$} \\
\hline \multirow[b]{2}{*}{3} & ACEQUIA DEL CAMINÀS & 30S 741798.31 E 4324417.68 & 1 \\
\hline & \multicolumn{3}{|c|}{$\begin{array}{l}\text { Lemnetum gibbae (W.Koch 1954) Miyawaki \& R. Tx. } 1960 \\
\text { Asociación formada por poblaciones casi monoespecíficas de Lemna gibba, aunque algunas veces } \\
\text { acompañadas de Lemna minor. Ocupa biotopos ligeramente salobres en la desembocadura de ríos, } \\
\text { canales y acequias en aguas estancadas o con poca corriente, por lo común muy contaminadas } \\
\text { (Soriano Guarinos, 1995). }\end{array}$} \\
\hline \multirow[b]{2}{*}{4} & ACEQUIA DEL CAMINÀS & 30S 741855.92 E 4324431.48 & 1 \\
\hline & \multicolumn{3}{|c|}{ ASOCIACIONES VEGETALES } \\
\hline
\end{tabular}

Tabla 1. Zonas de muestreo: tipo de estación, coordenadas GPS, altura sobre el nivel del mar y asociaciones vegetales. Table 1. Sampling zones: station type, GPS coordinates, height above mean sea level and vegetal associations. 


\section{Muestreo larvario}

Para el muestreo de las poblaciones larvarias de culícidos se ha empleado la técnica del dipping, que permite recolectar estadios inmaduros en aquellos cuerpos de agua donde los mosquitos se desarrollan, utilizando para ello un recipiente de $350 \mathrm{ml}$ de capacidad y $10 \mathrm{~cm}$ de diámetro de boca. Este artilugio fue introducido en cinco ocasiones en cada una de las zonas de muestreo y de forma quincenal desde principios de mayo hasta finales de octubre de 2012, utilizándose el mismo esfuerzo en todos los puntos en cada ocasión. Las muestras recolectadas se procesaban tras cada jornada en el laboratorio, donde se eutanasiaban y se conservaban para su estudio en alcohol $70 \%$. Cuando el nivel de desarrollo de las larvas no permitía su identificación, se dejaba completar su crecimiento en botes eclosionadores hasta alcanzar el estadio IV, momento en el cual se procedía al procesamiento. Para la identificación específica se visualizó mediante lupa binocular cada individuo usando para la identificación taxonómica la clave de Schaffner et al. (2001). Las pupas se dejaron en botes eclosionadores hasta completar su desarrollo a adulto. Previa eutanasia, se identificaron las hembras adultas con la ayuda de la clave de Schaffner et al. (2001), en fresco bajo lupa binocular. Previo montaje de las genitalias en líquido de Hoyer, se identificaron al microscopio los machos utilizando, en este caso, el trabajo de Becker et al. (2003).

\section{Resultados y discusión}

Entre mayo y octubre de 2012 se colectaron en el marjal de Xeraco-Xeresa un total de 30.709 culícidos, pertenecientes todos ellos a la especie $C x$. pipiens, hecho que pone de manifiesto la incontestable dominancia de este díptero en este tipo concreto de ambiente. Según Bueno-Marí et al. (2010), aunque comparativamente Cx.pipiens muestra una adaptabilidad similar a todos los biotopos en Valencia, sus colectas son mucho más frecuentes en acequias y canales. Es por ello que este culícido es un claro ejemplo de organismo eurioico, pues resiste amplias variaciones de las condiciones ambientales y su capacidad de adaptación es elevada. En consecuencia puede explotar una gran variedad de nichos, desde aguas extremadamente eutrofizadas e incluso contaminadas a aguas no contaminadas, con diferentes gradientes físico-químicos y en reservorios de muy diversa naturaleza, como recipientes artificiales de pequeño tamaño pasando por márgenes de ríos hasta, como es el caso, acequias y canales (AlarcónElbal, 2013). Esta especie, además del notable rol en la transmisión de VNO, también es vector de otros arbovirus, como Tahyna o Sindbis, y de parásitos: dirofilarias de afección veterinaria e inclusive humana y plasmodios aviares (Schaffner et al. 2001).

Nuestra comparativa zonal muestra que, aun encontrándose todas las estaciones en un radio no superior a los 400 metros y perteneciendo tres de ellas (Zona 1, 3 y 4) a la misma acequia (Acequia del Caminàs), el número de individuos capturados en una y otra zona es extremadamente desigual, concentrándose el 99,9\% de capturas entre la Zona $2(58,4 \%)$ y la Zona $4(41,5 \%)$, es decir, aquellas en las que encontramos L. grandiflora. Estas plantas de la familia Onagraceae, también conocidas como onagrarias o duraznillos de agua, enraízan bajo el agua y tienen una parte aérea que alcanza cerca del metro de longitud. Biológicamente se caracterizan por presentar una gran capacidad de colonización y propagación, produciendo una elevada biomasa que puede cubrir toda la superficie del cuerpo de agua, lo cual altera el ecosistema completo mediante la reducción de la transmisión de luz, el flujo de agua y el contenido de oxígeno, así como por la sedimentación creciente (Nehring \& Kolthoff, 2011). Por el contrario, en la Zona $1(0,08 \%)$, que carece de vegetación en superficie pero está abrigada por comunidades palustres ricas en juncos y eneas en la orilla de la acequia, cuya asociación más extendida es la del carrizal con enea (Typho-Scirpetum tabernaemontani), como la Zona $3(0,02 \%)$, que está invadida por Lemna gibba, el número de capturas es prácticamente anecdótico. Este hecho fue constante durante los seis meses que duró el muestreo, evidenciando una tendencia extremadamente marcada hacia aquellas aguas colonizadas por el vegetal alóctono de origen americano L. grandiflora. Las especies flotantes del género Lemna L. (Lemnaceae) o lentejas de agua, tapizan grandes superficies de agua en tal medida que, además de hacer desaparecer la vegetación sumergida y eutrofizar el medio, impiden que las hembras de mosquitos puedan realizar la puesta de huevos. Asimismo, dificultan el desarrollo de las larvas por medio de 


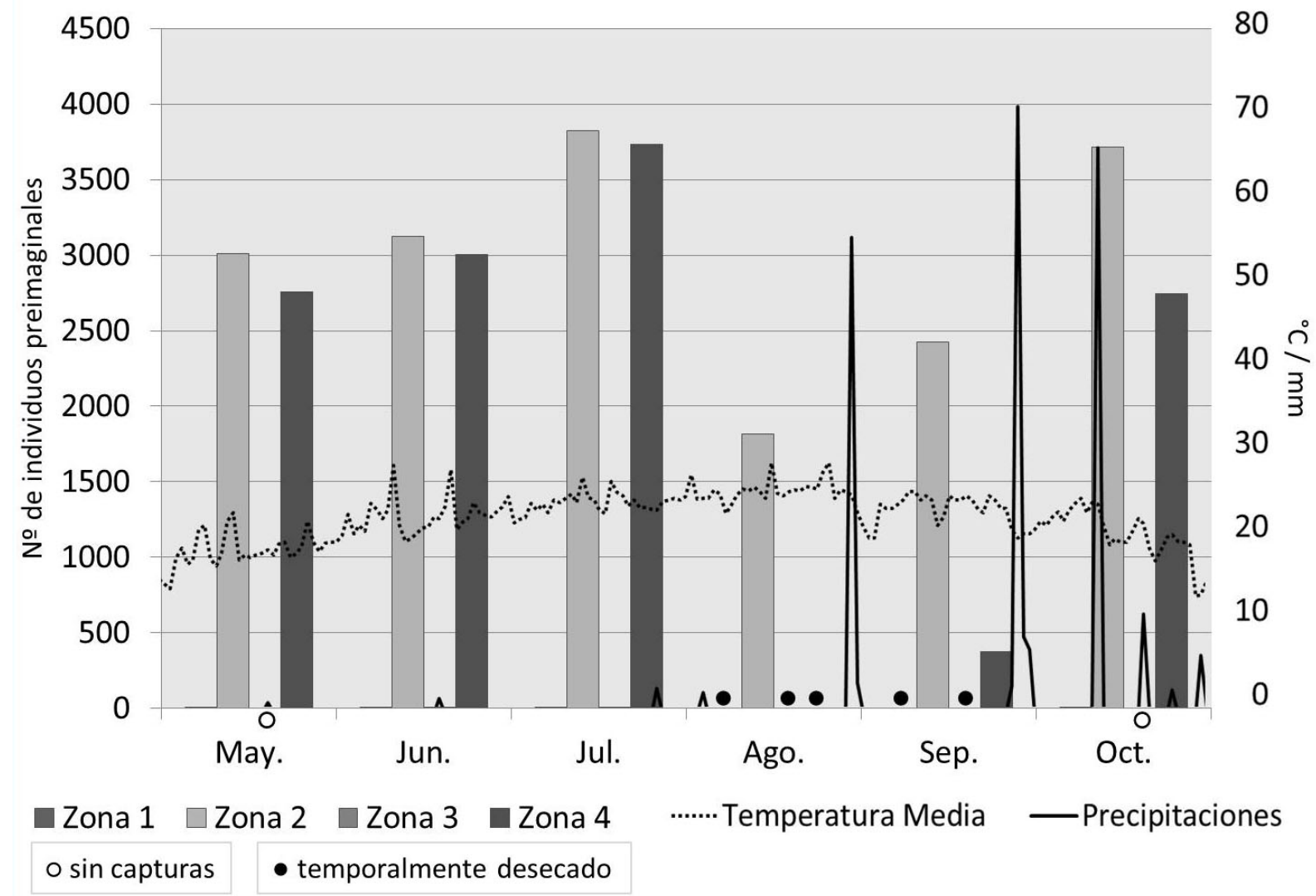

Figura 2. Individuos recolectados en las zonas de muestreo, temperatura media y precipitación entre mayo y octubre de 2012. Figure 2. Collected specimens in each sampling zone, average temperature and rainfall between May and October 2012.

semioquímicos como sinomonas y comprometen la respiración de oxígeno atmosférico con su biomasa laminar (Eid et al. 1992; Cuda, 2009), hecho que explica la exigua cantidad de mosquitos colectados en la Zona 3 (Fig. 2).

Fenológicamente hablando, se evidencia una mayor abundancia de individuos preimaginales conforme aumenta la temperatura media en la zona, siendo el mes de julio el que más capturas registró. A partir de este mes entra en juego otro factor: la precipitación. En el año 2012 nos encontramos con un período estival muy seco en el este peninsular, con precipitaciones dispersas y muy puntuales. Estas acequias y canales son puntos hídricos semipermanentes, cuyas entradas de agua son principalmente por infiltración, escorrentía y lluvia, por lo que en los meses más calurosos es habitual que lleguen a secarse por completo de no existir un adecuado aporte hídrico que compense la pérdida por evaporación. En agosto y tras el incremento de la temperatura y las escasísimas precipitaciones, la Acequia del Caminàs (considerablemente más pequeña que la Acequia Travessera) se desecó en todos los puntos de muestreo, quedando tan solo la vegetación hidrófita, en la Zona 4. Esta pronunciada sequía fue el motivo por el cual no se registró ninguna captura en las Zonas 1, 3 y 4 durante este mes y el siguiente, aunque es cierto que a finales de septiembre y coincidiendo con unos días lluviosos, donde se registró la mayor cantidad de precipitación del período de estudio, la Zona 4 fue capaz de albergar algunos centímetros de agua que permitieron una nueva y rápida proliferación de mosquitos en este punto. Durante este periodo más seco, la Zona 2 sufrió asimismo una considerable bajada del nivel de agua, pero todavía conservó algunos decímetros que hicieron perfectamente viable el desarrollo de las larvas. Aun así se registró una disminución en la cantidad de individuos durante estos meses (agosto y septiembre), que coincidió en este caso con una modificación ambiental (de origen desconocido) a principios de agosto mediante la cual se eliminó gran cantidad de biomasa vegetal, quedando la Acequia Travessera en este punto significativamente despoblada de L. grandiflora, en compara- 


\begin{tabular}{|l|c|c|c|c|c|c|c|c|}
\cline { 2 - 10 } \multicolumn{1}{c|}{} & \multicolumn{2}{c|}{ Zona 1 } & \multicolumn{2}{c|}{ Zona 2 } & \multicolumn{2}{c|}{ Zona 3 } & \multicolumn{2}{c|}{ Zona 4 } \\
\cline { 2 - 10 } \multicolumn{1}{c|}{} & $\mathrm{n} / \mathrm{dip}$ & $\mathrm{n} / \mathrm{dm}^{3}$ & $\mathrm{n} / \mathrm{dip}$ & $\mathrm{n} / \mathrm{dm}^{3}$ & $\mathrm{n} / \mathrm{dip}$ & $\mathrm{n} / \mathrm{dm}^{3}$ & $\mathrm{n} / \mathrm{dip}$ & $\mathrm{n} / \mathrm{dm}^{3}$ \\
\hline Mayo & 0,3 & 0,8 & 301,0 & 860,0 & 0 & 0 & 275,6 & 787,4 \\
\hline Junio & 0,7 & 2,0 & 312,6 & 893,1 & 0,2 & 0,6 & 300,1 & 857,4 \\
\hline Julio & 0,8 & 2,3 & 382,6 & $1.093,1$ & 0,5 & 1,4 & 373,2 & $1.066,3$ \\
\hline Agosto & - & - & 181,5 & 518,6 & - & - & - & - \\
\hline Septiembre & - & - & 242,7 & 693,4 & - & - & 37,5 & 107,1 \\
\hline Octubre & 0,6 & 1,7 & 371,7 & $1.062,0$ & 0 & 0 & 274,4 & 784,0 \\
\hline Total & 0,4 & 1,1 & 298,6 & 853,14 & 0,1 & 0,3 & 212,6 & 607,4 \\
\hline
\end{tabular}

Tabla 2. Densidad media de individuos colectados por mes, donde n/dip es el número medio de ejemplares colectados por dipper, n/dm3 es el número medio de ejemplares colectados por decímetro cúbico (litro) y el símbolo - marca aquellos meses en los que no hubo capturas por estar la zona sin agua.

Table 2. Average density of collected specimens by month, where $\mathrm{n} /$ dip is the average of specimens collected by dipper, $\mathrm{n} / \mathrm{dm} 3$ the average of specimens collected by cubic decimeter (liter), and symbol - marks the months without captures due the desiccation.

ción con meses anteriores en el periodo de estudio. El clima mediterráneo dominante posibilita un mantenimiento de la temperatura media cercana a $\operatorname{los} 20^{\circ} \mathrm{C}$ en los primeros meses del otoño, por lo que las condiciones climáticas, a las cuales se le suma la elevada humedad relativa propia del ambiente costero, viabilizan la existencia de poblaciones del mosquito hasta bien entrada la época otoñal.

En cuanto a abundancias medias (Tabla 2), teniendo en cuenta la periodicidad quincenal del muestreo y el esfuerzo constante realizado, se obtiene una media total de los seis meses para cada zona de 0,4 ejemplares/dipper (1,1 ejemplares/ $\left.\mathrm{dm}^{3}\right)$ en la Zona 1, 298,6 ejemplares/dipper $(853,1$ individuos $/ \mathrm{dm}^{3}$ ) en la Zona 2, 0,1 ejemplares/dipper $\left(0.3\right.$ ejemplares $\left./ \mathrm{dm}^{3}\right)$ en la Zona 3 y 212,6 ejemplares/dipper $\left(607,4\right.$ ejemplares $\left./ \mathrm{dm}^{3}\right)$ en la Zona 4. El mes de julio es cuando se registra un mayor número de capturas, por lo que la media de este periodo en concreto asciende a 382,6 ejemplares/dipper $\left(1093,1\right.$ ejemplares $\left./ \mathrm{dm}^{3}\right)$ en la Zona 2 y 373,2 ejemplares/dipper (1.066,3 ejemplares/ $\mathrm{dm}^{3}$ ) en la Zona 4, lo que viene a suponer una densidad de individuos preimaginales elevadísima en las acequias colonizadas por L. grandiflora, superando esta media los 1.000 ejemplares por litro en ambos puntos de la Acequia Travessera y Acequia del Caminàs. Es igualmente significativa la gran densidad que encontramos incluso en los primeros meses del estudio, que corresponden con el ecuador de la primavera y donde ya se alcanzan unas cantidades muy elevadas en los puntos colonizados por esta planta.
Los trabajos que estudian la relación que ejercen ciertas plantas acuáticas sobre las poblaciones de culícidos son escasos en nuestro país, si bien hay algunos documentos antiguos de gran valor realizados en Levante que ponen de manifiesto la influencia negativa que ejercen ciertas especies del género Chara L. en mosquitos con interés vectorial (Caballero, 1920; Pardo, 1923). En la Comunidad Valenciana, al igual que para toda la Península Ibérica, se han citado tradicionalmente tres taxones del género Ludwigia L., siendo sobre todo $L$. grandiflora la especie alóctona que representa la mayor amenaza para los hábitats naturales, remontándose los primeros registros tres décadas atrás en la provincia de Valencia (Carretero, 1996). Los efectos de algunos hidrófitos pertenecientes a este género en relación a la proliferación de culícidos no es un acontecimiento novedoso. En la zona costera del estado de California (suroeste de los EE.UU.), en los humedales que componen la Laguna de Santa Rosa (Condado de Sonoma), se ha constatado la estrecha asociación entre este hidrófito invasor y el incremento de las poblaciones de culícidos tales como Cx. pipiens, Culex erythrothorax Dyar, 1907, Culex tarsalis Coquillett, 1896 y Culiseta particeps (Adams, 1903). En este enclave, la elevada densidad de Ludwigia hexapetala (Hook. \& Arn.) ha supuesto un grave problema de salud pública en tanto en cuanto estas plantas han creado un hábitat idóneo para el desarrollo de mosquitos vectores de VNO además de impedir en gran medida todas las actividades de control desarrolladas, generando graves pérdidas económicas y afectando seriamente 
la calidad de las aguas colonizadas. En algunas áreas con presencia de este elemento alóctono, las poblaciones de mosquitos colectadas superan en 100 veces los valores considerados como aceptables (Sears \& Verdone, 2005). Estudios realizados en la misma dirección señalan, esta vez en el estado de Delaware (este de EE.UU.), una fuerte asociación de Ludwigia sp. y Cx. pipiens (Gingrich et al. 2006). Además, algunas especies como $L$. grandiflora colonizan frecuentemente los arrozales $\mathrm{y}$, por tanto, sus efectos superan el ámbito ecológico y añaden pérdidas económicas. Estos casos no pueden más que llevarnos a pensar en el hecho de que el establecimiento de este hidrófito en los humedales levantinos, así como el de otros invasores de características biológicas similares, puede condicionar la aparición de emergencias sanitarias de mano de estos dípteros, a semejanza de situaciones similares acaecidas en otras regiones geográficas. Algunas de estas regiones poseen unas características bioclimáticas muy semejantes a las nuestras, como es el caso de la costa californiana, cuyo clima es eminentemente mediterráneo.

Dentro de este contexto cabe señalar la gran importancia de las costas de restinga y albufera en la Comunidad Valenciana, las cuales abarcan más de la mitad del litoral. Conforman un corredor de humedales dulceacuícolas, albuferas y marjales antropizados en mayor o menor medida que se extienden desde la desembocadura del Sénia hasta las Lagunas de la Mata y Torrevieja (Eguibar Galán et al. 2007), catalogándose un total de 48 zonas húmedas que se desarrollan en aproximadamente 45.000 hectáreas (Meteache, 1998). Esto convierte al sistema de humedales valenciano en uno de los más densos y mejor distribuidos de toda Europa. Estos complejos ecológicos, siendo buen ejemplo de ello el que nos ocupa en esta investigación, acogen una gran cantidad de avifauna autóctona y migrante, además de estar localizados cerca de núcleos urbanos que en la época estival conforman nodos de concentración turística de primer nivel. Esto significa que, epidemiológicamente hablando, nos encontramos con una conjunción espacial y temporal (en un ambiente rural pero también urbano) de varios factores en connivencia y a su vez determinantes en la transmisión de esta arbovirosis: hospedadores primarios (aves acuáticas), vector principal (Cx. pipiens) y hospedadores accidentales (población humana). A ello hay que sumarle la confirmación de la circulación del VNO en el país (Figuerola et al. 2008) y unas características ecológicas y climatológicas favorables para el mantenimiento del ciclo y el óptimo desarrollo del vector a nivel mediterráneo, convirtiéndose esta zona en un punto con una gran potencialidad para que se produzca el salto en la trasmisión del ciclo enzoótico al epizoótico. Teniendo en cuenta estos factores, la aparición de una epidemia con elevada incidencia humana es un hecho más que probable en España, sobre todo en la vertiente mediterránea del país.

A este respecto es fundamental volver sobre la estrecha asociación existente entre esta arbovirosis y las aves migratorias. Son estos vertebrados los hospedadores definitivos y amplificadores primarios del virus así como los principales diseminadores (Malkinson \& Banet, 2002), reintroduciendo ocasionalmente el virus en las zonas templadas cuando regresan de sus áreas de invernada en las que éste es endémico (Nasci et al. 2001), aunque también se ha aislado el virus en aves residentes y sinantrópicas como Columbiformes (Allison et al. 2004). Muchas especies de aves migran para aprovecharse de las diferencias estacionales de temperatura en el mundo, con lo que optimizan la disponibilidad de fuentes de alimento $y$ de hábitats reproductivos; no obstante el proceso acarrea una serie de riesgos tales como la predación, el parasitismo y hasta la muerte (Lotta-Arévalo, 2010). En estos largos trayectos, frecuentemente intercontinentales, pueden diseminar el virus desde el lugar de infección a otras localizaciones muy alejadas. Con la reaparición epidémica del VNO en algunos países europeos, el interés se ha centrado una vez más en el origen africano del agente causal, vehicularizado por aves silvestres en sus movimientos migratorios (Malkinson \& Banet, 2002). Los humedales valencianos están situados en plena ruta migratoria del Mediterráneo Occidental, lugar de paso de muchas aves migratorias que regresan de África (donde el VNO es endémico) hacia el norte de Europa para iniciar en primavera el proceso natural de reproducción. Es por ello que el riesgo de introducción de patógenos africanos en los humedales levantinos es alto desde el mes de marzo hasta julio, correspondiéndose con la migración primaveral de estas aves transaharianas y su época de cría (Jourdain et al. 2007). Además, no se descarta que aves con otras rutas migratorias como la ruta Atlántica o la ruta 
del Mar Negro-Mediterráneo puedan, directa o indirectamente, posibilitar la aparición de focos en Europa occidental. Dicho de otro modo, dada la estratégica situación geográfica de España en relación con el paso de aves migratorias entre Europa y África y la relevancia de nuestros humedales como destacados ecosistemas con áreas de nidificación de muchas de estas aves, nuestro país se encuentra ante un riesgo real de aparición de brotes (MAGRAMA, 2012).

En conclusión, el crecimiento descontrolado de estas especies exóticas de agua dulce proporciona con asiduidad un hábitat ideal donde los mosquitos pueden proliferar desmedidamente y el caso del marjal de Xeraco-Xeresa es un claro ejemplo de ello. La comprensión de los factores que facilitan o impiden la reproducción de estos artrópodos es vital para adoptar medidas de control adecuadas e implementar sistemas de vigilancia activos y sostenidos en el tiempo. Consideramos que un enfoque interdisciplinar es primordial para alcanzar este objetivo. El control de muchas enfermedades emergentes y reemergentes de carácter vectorial dependerá, en su casi entera totalidad, del establecimiento y fortalecimiento de sistemas de vigilancia entomológica eficientes y coordinados, a nivel nacional e internacional. Aunque estas enfermedades no entienden de fronteras, ciertos cambios en la conducta humana encaminados a reducir su impacto negativo en el medio ambiente asegurarían reducir estos riesgos. La formación de personal técnico y profesional, el fomento de estas líneas de investigación y el acceso a la educación y a la información sobre dichas temáticas para el conjunto de la población son las columnas sobre las que construir un futuro más sano y seguro, de otro modo se antoja una tarea ímproba obtener éxito en la prevención de estas enfermedades vehicularizadas por artrópodos.

\section{Agradecimientos}

Los autores deseamos expresar nuestra más sincera gratitud al Dr. Borja Cascales-Miñana (CNRSAMAP, Montpellier) y a la Dra. Pilar Soriano Guarinos (Universitat de València-Jardí Botànic de València) por su desinteresada contribución sobre aspectos relacionados con la caracterización botánica del estudio. Del mismo modo, queremos mostrar nuestro agradecimiento a nuestro colega Juan Rueda Sevilla (Universitat de València-
Departamento de Microbiología y Ecología) por el importante material bibliográfico facilitado. Asimismo nos gustaría agradecer el trabajo de los dos revisores anónimos, cuyos comentarios y sugerencias han contribuido a mejorar significativamente la calidad de este modesto trabajo. Por último, "encarecidas gracias" al Gobierno de España por apoyar a la investigación y a la ciencia en este país de una forma tan particular como generosa.

\section{Referencias}

Alarcón-Elbal PM, Delacour-Estrella S, Ruiz-Arrondo I, Pinal R, Muñoz A, Oropeza V, Carmona-Salido VJ, Estrada R \& Lucientes J. 2012. Los culícidos (Diptera, Culicidae) del valle medio del Ebro I: La Rioja (Norte de España). Boletín de la Sociedad Entomológica Aragonesa (S.E.A.) 50: 359-365.

Alarcón-Elbal PM. 2013. Plantas invasoras acuáticas y culícidos: un binomio peligroso. Boletín de la Real Sociedad Española de Historia Natural - Sección Biológica 107 (en prensa). Disponible en http://rshn.geo.ucm.es/cont/publis/boletines/179.pdf

Allison AB, Mead DG, Gibbs SEJ, Hoffman DM, Stallknecht DE. 2004. West Nile virus viremia in wild rock pigeons. Emerging Infectiuos Diseases 10(12): 2252-2255.

Becker N, Petric D, Zgomba M, Boase C, Dahl C, Lane J \& Kaiser A. 2003. Mosquitoes and their control. New York: Kluwer Academic/Plenum Publishers.

Bofill D, Domingo C, Cardenosa N, Zaragoza J, de Ory F, Minguell S, Sánchez-Seco MP, Domínguez A \& Tenorio A. 2006. Human West Nile virus infection, Catalonia, Spain. Emerging Infectious Diseases 12: 1163-1164.

Bueno-Marí R, Corella-López E \& Jiménez-Peydró R. 2010. Culícidofauna (Diptera: Culicidae) presente en los distintos enclaves hídricos de la ciudad de Valencia (España). Revista Colombiana de Entomología 36 (2): 235-241.

Caballero A. 1920. Las especies del género Chara y las larvas de los mosquitos. Trabajo del Laboratorio de Hidrobiología Española, 10. Anales del Instituto General y Técnico de valencia, 7 (29), 17 pp.

Carretero JL. 1996. Aportaciones a la distribución y ecología de las hepáticas y cormofitos acuáticos sumergidos y flotantes de la provincia de Valencia (España). Ecología 10: 257-272.

Centers for Disease Control and Prevention, National Center for Emerging and Zoonotic Infectious Diseases (NCEZID) \& Division of Vector-Borne Diseases (DVBD). 2012. 2012 West Nile virus update: December 11. Disponible en http://www.cdc.gov/ ncidod/dvbid/westnile/index.htm (accedido el 15 de enero de 2013)

Cuda JP. 2009. Chapter 5: Aquatic plants, mosquitoes and public health. En Best Management Practices Manual for Aquatic Plants. Haller WT, Gettys LA \& Bellaud M, Eds. Aquatic Ecosystem Restoration 
Foundation. Marietta, Georgia. pp. 31-34.

Eguibar Galán MA, Sanchis Ibor C, Marco Segura JB \& Mateu Bellés JF. 2007. El catálogo de zonas húmedas de la Comunidad Valenciana. Aspectos metodológicos. Ingeniería del Agua 14 (1): 23-35.

Eid MAA, Kandil MAE, Moursy EB \& Sayed GEM. 1992. Effect of the duck-weed, Lemna minor vegetations on the mosquito, Culex pipiens pipiens. International Journal of Tropical Insect Science 13: 357-361.

Eidson M, Komar N, Sorhage F, Nelson R, Talbot T \& Mostashari F. 2001. Crow deaths as a sentinel surveillance system for West Nile virus in the Northeastern United States, 1999. Emerging Infectious Diseases 7: 615-620.

Fernández-Salas I, Garza-Rodríguez ML, Beaty BJ, Ramos-Jiménez J \& Rivas-Estilla AM. 2007. Presencia del virus del oeste del Nilo en el noreste de México. Salud Pública de México 49: 210-217.

Figuerola J, Jiménez-Clavero MA, López G, Rubio C, Soriguer R, Gómez-Tejedor C \& Tenorio A. 2008. Size matters: West Nile virus neutralizing antibodies in resident and migratory birds in Spain. Veterinary Microbiology 132: 39-46.

Gingrich JB, Robert D, Williams GM, O Connor L \& Harkins K. 2006. SWMPs, constructed wetlands, and other best management practices as potential breeding sites for West Nile Virus vectors in Delaware during 2004. Journal of American Mosquito Control Association 22(2): 282-291.

Hayes EB, Komar N, Nasci RS, Montgomery SP, O'Leary DR \& Campbell GL. 2005. Epidemiology and transmission dynamics of West Nile virus disease. Emerging Infectious Diseases 11: 1167-1173.

Higgs S, Snow K \& Gould EA. 2004. The potential for West Nile virus to establish outside of its natural range: a consideration of potential mosquito vectors in the United Kingdom. Transactions of the Royal Society of Tropical Medicine and Hygiene 98: 82-87.

Hubálek Z. 2000. European experience with the West Nile virus ecology and epidemiology: could it be relevant for the New World? Viral Immunology 13: 415426.

Jourdain E, Gauthier-Clerc M, Bicout D \& Sabatier P. 2007. Bird migration routes and risk for pathogen dispersion into western Mediterranean wetlands. Emerging Infectious Diseases 13 (3): 365-372.

Kaptoul D, Viladrich PF, Domingo C, Niubó J, MartínezYélamos S, De Ory F \& Tenorio A. 2007. West Nile virus in Spain: report of the first diagnosed case (in Spain) in a human with aseptic meningitis. Scandinavian Journal of Infectious Diseases 39: 70-71.

Kramer LD, Styer LM \& Ebel GD. 2008. A global perspective on the epidemiology of West Nile virus. Annual Review of Entomology 53: 61-81.

Lotta Arévalo IA. 2010. Presencia de simúlidos ornitofílicos en el Parque Nacional Natural (PNN) Chingaza: implicaciones en la transmisión del hemoparásito Leucocytozoon sp. Tesis de Maestría. Facultad de Medicina, Universidad Nacional de Colombia.

Madsen JD. 2009. Chapter 1: Impact of invasive aquatic plants on aquatic biology. En Best Management Practices Manual for Aquatic Plants. Haller WT,
Gettys LA \& Bellaud M, Eds. Aquatic Ecosystem Restoration Foundation. Marietta, Georgia. pp. 1-8.

Malkinson M \& Banet C. 2002. The role of birds in the ecology of West Nile virus in Europe and Africa. Current Topics in Microbiology and Immunology 267: 309-322.

Mateache P. 1998. Catálogo de zonas húmedas de la Comunidad Valenciana (España). SEHUMED 5: 1-3.

Ministerio de Agricultura, Alimentación y Medio Ambiente (MAGRAMA). 2012. Plan de Vigilancia de la Encefalitis del Oeste del Nilo 2012 (West Nile) en España. Disponible en: http://rasve.mapa.es/pub lica/programas/NORMATIVA\%20Y\%20PROGRAMA S\%5CPROGRAMAS $\% 5 C 2012 \% 5$ CENCEFALITIS\% 20DEL\%20OESTE\%20DEL\%20NILO\%5CPLAN\%2 ODE\%20VIGILANCIA\%20DE\%20LA\%20ENCEFALI TIS\%20DEL\%20OESTE\%20DEL\%20NILO\%20201 2.PDF (accedido el 15 de enero de 2013).

Nasci RS, Savage HM, White DJ, Miller JR, Cropp BC, Godsey MS, Kerst AJ, Bennett P, Gottfried K \& Lanciotti RS. 2001.West Nile virus in overwintering Culex mosquitoes, New York City, 2000. Emerging Infectious Diseases 7: 742-744.

Nash D, Mostashari F, Fine A, Miller J, O'Leary D, Murray K, Huang A, Rosenberg A, Greenberg A, Sherman M, Wong S \& Layton M. 2001. The outbreak of West Nile virus infection in the New York City area in 1999. The New England Journal of Medicine 344: 1807-1814.

Nehring S \& Kolthoff D. 2011. The invasive water primrose Ludwigia grandiflora (Michaux) Greuter \& Burdet (Spermatophyta: Onagraceae) in Germany: First record and ecological risk assessment. Aquatic Invasions 6 (1): 83-89.

Pardo L. 1923. Observaciones acerca de la acción de la Chara sobre las larvas de los mosquitos. Boletín de la Real Sociedad Española de Historia Natural 23: 154-157.

Peña M, Alfaro R, González MA \& Aparicio JV. 2005. IX Los sistemas de riego tradicional de las marjales. En Los riegos de La Safor y La Valldigna. Agua, territorio y tradición. Ed. Dirección General de Patrimonio Cultural Valenciano, Consellería de Cultura y Educación y Generalitat Valenciana. Valencia, pp. 141-150.

Pérez Ruiz S, Sanbonmatsu Gámez S \& Jiménez Clavero MA. 2011. Infección por virus West Nile. Enfermedades Infecciosas y Microbiología Clínica 29: 21-26.

Rappole JH, Derrickson SR \& Hubálek Z. 2000. Migratory birds and spread of West Nile Virus in the Western Hemisphere. Emerging Infectious Diseases 6: 319-328.

Rodrigo MA, Rojo C, Armengol X \& Mañá M. 2001. Heterogeneidad espacio-temporal de la calidad del agua en un humedal costero: El Marjal de la Safor (Valencia). Limnetica 20 (2): 329-339.

Ruiz Téllez T, López EM, Granado G, Pérez EA, López RM \& Sánchez Guzmán JM. 2008. The Water Hyacinth, Eichhornia crassipes: an invasive plant in the Guadiana River Basin (Spain). Aquatic Invasions 3 (1): 42-53. 
Savage H, Ceianu C, Nicolescu G, Karabatsos N, Lanciotti R, Vladimirescu A, Laiv L, Ungureanu A, Romanca C \& Tsai TF. 1999. Entomologic and avian investigations of an epidemic of West Nile fever in Romania in 1996, with serologic and molecular characterization of a virus isolate from mosquitoes. American Journal of Tropical Medicine and Hygiene 61: 600-611.

Schaffner F, Angel G, Geoffroy B, Hervy JO \& Rhaeim A. 2001. The mosquitoes of Europe / Les moustiques d' Europe. Montpellier, France: IRD Éditions and EID Méditerranée.

Sears ALW \& Verdone LN. 2005. Ludwigia hexapetala management plan for the Laguna de Santa Rosa, Sonoma County, California. California: The Sonoma County Ludwigia Task Force. \# 2005-2010.

Soriano Guarinos P. 1995. Estudio de la vegetación y la flora de la comarca de La Safor, Valencia. Tesis Doctoral. Universidad de Valencia. Facultad de Farmacia, Departamento de Biología Vegetal.

Vázquez González A. 2010. Búsqueda de flavivirus en mosquitos de humedales españoles. Análisis molecular del virus West Nile y otros flavivirus. Tesis Doctoral. Universidad Complutense de Madrid. Facultad de Veterinaria, Departamento de Sanidad Animal.

Villena MJ \& Romo S. 2001. Fitoplancton de dos lagunas de los humedales de Xeresa y Xeraco (Valencia, España). Botanica Complutensis 25: 179-189.

Zeller HG \& Schuffenecker I. 2004. West Nile virus: an overview of its spread in Europe and the Mediterranean basin in contrast to its spread in the Americas. European Journal of Clinical Microbiology \& Infectious Diseases 23: 147-156. 